\title{
Formation of Icosahedral Phase in Bulk Glass Forming Ti-Zr-Be-Cu-Ni Alloy
}

*Correspondence to:

Lee JK,

Tel: $+82-41-521-9388$

Fax: +82-41-568-5776

E-mail: jklee71@kongju.ac.kr

Received June 19, 2015

Revised June 24, 2015

Accepted June 24, 2015

\author{
Jin Man Park, Jun Hyeok Lee ${ }^{1}$, Mi Seon Jo ${ }^{1}$, Jin Kyu Lee ${ }^{1, *}$ \\ Global Technology Center, Samsung Electronics., Ltd., Suwon 443-742, Korea
Materials Engineering, Kongju National University, Cheonan 331-717, Korea \\ Global Technology Center, Samsung Electronics., Ltd., Suwon 443-742, Korea
${ }^{1}$ Division of Advanced Materials Engineering, Kongju National University, Cheonan 331-717, Korea
}

\begin{abstract}
Formation of an icosahedral phase in the bulk glass forming $\mathrm{Ti}_{40} \mathrm{Zr}_{29} \mathrm{Be}_{14} \mathrm{Cu}_{9} \mathrm{Ni}_{8}$ alloy during crystallization from amorphous phase and solidification from melt is investigated. The icosahedral phase with a size of 10 to $15 \mathrm{~nm}$ forms as a thermodynamically stable phase at intermediate temperature during the transformation from amorphous to crystalline phases such as Laves and $\beta$-(Ti-Zr) phases, indicating that the existence of the icosahedral cluster in the undercooled liquid. On the other hand, the icosahedral phase forms as a primary solidification phase even though the Laves phase is stable at high temperature, which is can be explained based on the high nucleation rate of icosahedral phase relative to that of competing crystalline Laves phase due to lower interfacial energy between icosahedral and liquid phases.
\end{abstract}

Key Words: Quasicrystal, Icosahedral, Metallic glass, Ti-Zr-Be-Cu-Ni, Crystallization

\section{INTRODUCTION}

Precipitation of the icosahedral quasicrystalline phase from am amorphous matrix during annealing has recently attracted significant interest among scientists (Poon et al., 1985; Tsai et al., 1989; Holzer \& Kelton, 1991; Lee et al., 2000; Xing et al., 2002), because of its potential to give insight about the relationship between amorphous and quasicrystalline structure and the growth kinetics of quasicrystals in undercooled liquid. Additionally the homogeneous distribution of the nano-scaled icosahedral quasicrystalline phase in crystalline or amorphous matrix results in significant improvements in mechanical properties (Xing et al., 1999; Kim et al., 2003a; Ren et al., 2011). However, all the icosahedral phases are formed as a primary phase during crystallization from the amorphous phase in these alloy systems. On the other hand, Al-based (Shechtman et al., 1984), Ti-Zr-Ni (Kim \& Kelton, 1996) alloys form quasicrystals directly during rapid solidification from the melt. The formation of quasicrystalline phases during solidification from the melt has been reported in the glass-forming Zr-based alloy systems (Saida et al., 2000; Park et al., 2005; Qiang et al., 2006; Mei et al., 2008). The formation of quasicrystalline phase in the alloy systems with a high glass forming ability that enables the formation of bulk amorphous alloy, indicate that the alloys can expand the practical applications as structural materials.

In this study we report the formation of icosahedral phase in the bulk glass forming $\mathrm{Ti}_{40} \mathrm{Zr}_{29} \mathrm{Cu}_{9} \mathrm{Ni}_{8} \mathrm{Be}_{14}$ alloy during crystallization from amorphous phase and solidification from melt at low cooling rate.

\section{MATERIALS AND METHODS}

Alloys of nominal composition (at\%) $\mathrm{Ti}_{40} \mathrm{Zr}_{29} \mathrm{Be}_{14} \mathrm{Cu}_{9} \mathrm{Ni}_{8}$ was prepared by arc melting of high purity metals under an argon atmosphere. Rapidly solidified ribbon specimen was prepared under Ar atmosphere by melt spinning technique. The resulting ribbon exhibits thickness of about $30 \mu \mathrm{m}$ and

This work was supported by the Industrial Technology Innovation Program funded by the Ministry of Trade, Industry and Energy (MOTIE) and Korea Institute of Technology Evaluation and Planning (KETEP).

( ) This is an open-access article distributed under the terms of the Creative Commons Attribution Non-Commercial License (http://creativecommons.org/licenses/by-nc/4.0) which permits unrestricted noncommercial use, distribution, and reproduction in any medium, provided the original work is properly cited.

Copyrights @ 2015 by Korean Society of Microscopy 
width of about $2 \mathrm{~mm}$. The injection casting was performed to make bulk samples. Appropriate amounts of each alloy were remelted quartz tubes and injected through a nozzle into $\mathrm{Cu}$ mold, having cylindrical cavities of varying diameters from 4 to $6 \mathrm{~mm}$ and a height of around $50 \mathrm{~mm}$. The structure of the ribbon and bulk sample was analyzed by X-ray diffractometer (XRD, RINT2200; Rigaku, Japan) with $\mathrm{Cu} \mathrm{K \alpha}$ radiation and conventional transmission electron microscopy (TEM, 2000FX; JEOL, Japan) and high-resolution electron microscopy (HREM, 4000EX; JEOL). The thermal property of samples was investigated by differential scanning calorimetry (DSC, DSC7; Perkin Elmer, USA) under Ar atmosphere at a heating rate of $0.67 \mathrm{~K} / \mathrm{s}$.

\section{RESULTS AND DISCUSSION}

\section{Crystallization Behavior in $\mathrm{Ti}_{40} \mathrm{Zr}_{29} \mathrm{Be}_{14} \mathrm{Cu}_{9} \mathrm{Ni}_{8}$ Alloy}

Fig. 1 shows a DSC curve of the as melt-spun $\mathrm{Ti}_{40} \mathrm{Zr}_{29} \mathrm{Be}_{14} \mathrm{Cu}_{9} \mathrm{Ni}_{8}$ alloy at a heating rate of $0.67 \mathrm{~K} / \mathrm{s}$. The DSC curve exhibits two exothermic peaks with onset temperatures of 643 and $766 \mathrm{~K}$, respectively, and one high temperature endothermic peak with onset temperature of $829 \mathrm{~K}$. A clear glass transition is not observed the alloy. The two exothermic reactions correspond to a two-step crystallization process and the high temperature endothermic reaction corresponds to a solidstate transformation of a crystallization product into high temperature phase.

In order to identify the crystallization product for each reaction, heat treatments were separately performed up to the finishing temperature of the each reaction for the alloy. Fig. 2 shows a XRD trace obtained from the as melt-spun and heat-treated the $\mathrm{Ti}_{40} \mathrm{Zr}_{29} \mathrm{Be}_{14} \mathrm{Cu}_{9} \mathrm{Ni}_{8}$ ribbon alloy. The $\mathrm{XRD}$ trace from the as melt-spun specimen showed a broad diffraction peak, characteristic of the amorphous structure.

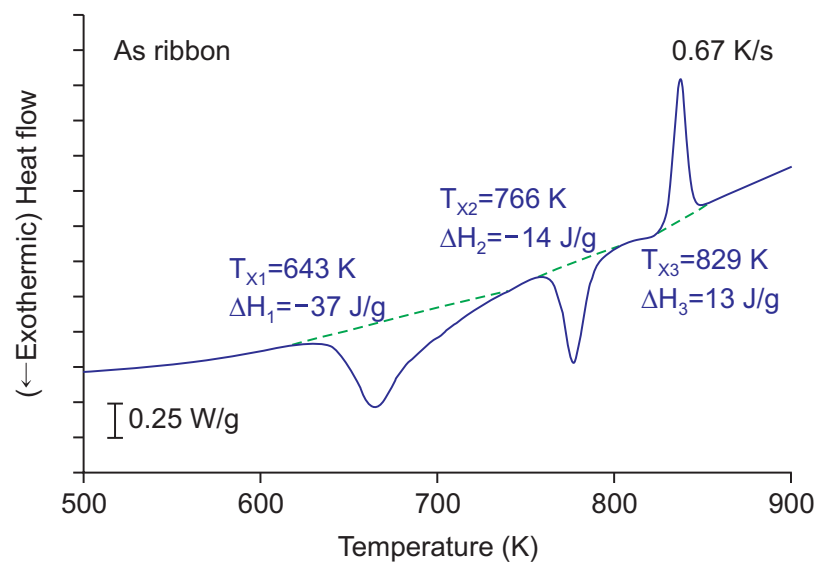

Fig. 1. Differential scanning calorimetry curve of the as melt-spun $\mathrm{Ti}_{40} \mathrm{Zr}_{29} \mathrm{Be}_{14} \mathrm{Cu}_{9} \mathrm{Ni}_{8}$ ribbon during continuous heating at a heating rate of $0.67 \mathrm{~K} / \mathrm{s}$.
The specimen heated up to the first exothermic reaction $(\mathrm{T}=763 \mathrm{~K})$ showed sharp diffraction peaks superimposed on a weak halo pattern, indicating a partial crystallization occurs during heat treatment. The diffraction peaks were analyzed to be an icosahedral phase with a quasilattice constant of $\mathrm{a}_{\mathrm{q}}=5.16 \AA$. The XRD trace from the alloy heated up to second exothermic reaction $(\mathrm{T}=813 \mathrm{~K})$ showed several sharp diffraction peaks from a mixture of an icosahedral phase and an $\mathrm{MgZn}_{2}$-type hexagonal Laves phase (C14). The $\mathrm{XRD}$ trace from the alloy heated up to $873 \mathrm{~K}$, corresponding to the endothermic reaction, showed sharp diffraction peaks from a mixture of a hexagonal Laves phase $(\mathrm{a}=5.23 \AA$ and $c=8.57 \AA)$ and a bcc solid solution $\beta$ - $(\mathrm{Ti}-\mathrm{Zr})$ phase. The icosahedral phase transformed into a Laves phase through the endothermic reaction, indicate that the icosahedral phase is more thermodynamically stable at a lower temperature than

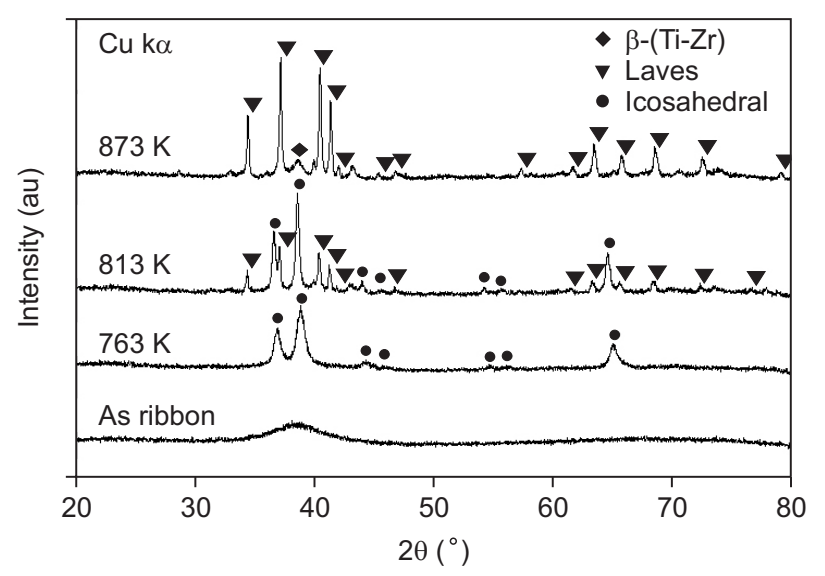

Fig. 2. $\mathrm{X}$-ray diffractometer traces of the as melt-spun and heat-treated $\mathrm{Ti}_{40} \mathrm{Zr}_{29} \mathrm{Be}_{14} \mathrm{Cu}_{9} \mathrm{Ni}_{8}$ alloy.

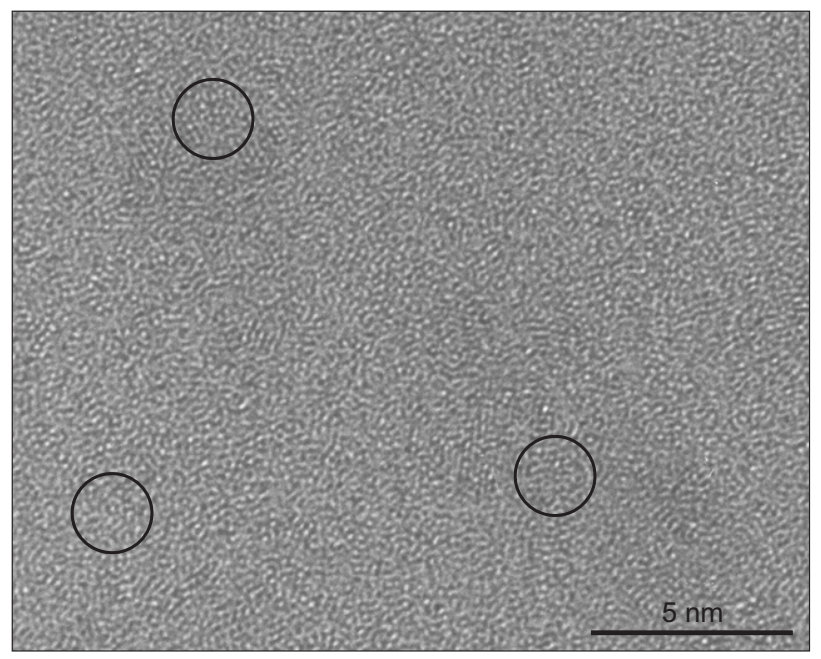

Fig. 3. High-resolution electron microscopy image of the as melt-spun $\mathrm{Ti}_{40} \mathrm{Zr}_{29} \mathrm{Be}_{14} \mathrm{Cu}_{9} \mathrm{Ni}_{8}$ alloy. 

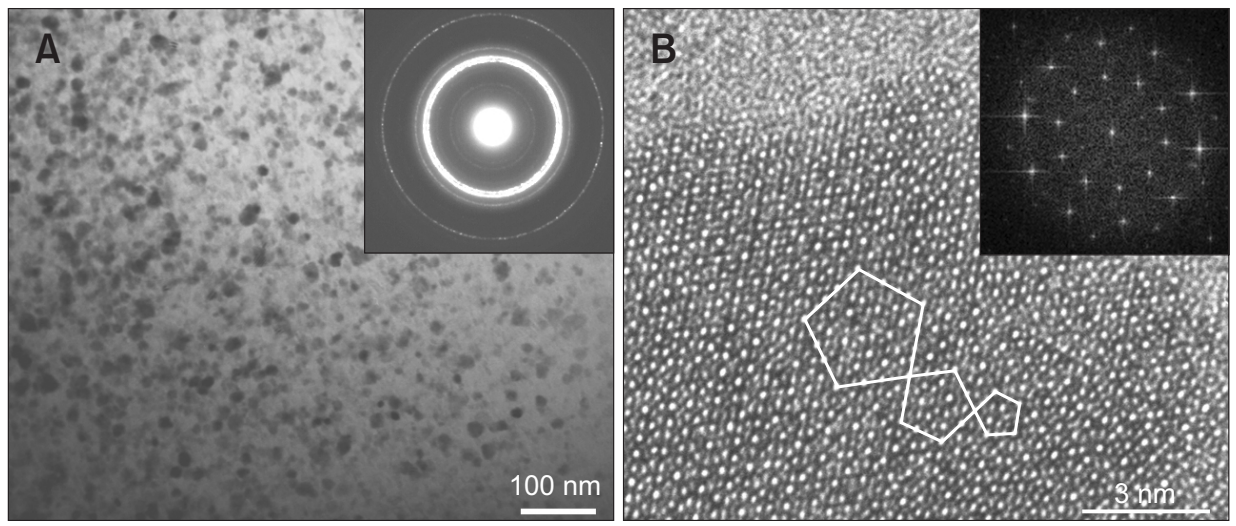

Fig. 4. Bright-field transmission electron microscopy image of the $\mathrm{Ti}_{40} \mathrm{Zr}_{29} \mathrm{Be}_{14} \mathrm{Cu}_{9} \mathrm{Ni}_{8}$ ribbon alloy heated up to $763 \mathrm{~K}(\mathrm{~A})$, selfaligned double patterning (inset in A), high-resolution electron microscopy image (B), and Fourier transformed pattern (inset in B).

the mixture of a Laves phase and a $\beta$ - $(\mathrm{Ti}-\mathrm{Zr})$ phase. Recently, reversible transformation from the Laves phase and $\beta-(\mathrm{Ti}-\mathrm{Zr})$ phase to icosahedral phase has been reported in Ti-based alloy (Kim et al., 2003b).

\section{Formation of Icosahedral Phase in Bulk Glass Forming $\mathrm{Ti}_{40} \mathrm{Zr}_{29} \mathrm{Be}_{14} \mathrm{Cu}_{9} \mathrm{Ni}_{8}$ Alloy}

Fig. 3 shows a HREM image of the as melt-spun $\mathrm{Ti}_{40} \mathrm{Zr}_{29} \mathrm{Be}_{14} \mathrm{Cu}_{9} \mathrm{Ni}_{8}$ alloy. The HREM image of the alloy shows a distribution of local ordered region as marked by circles, although the amorphous structure is confirmed by XRD and selected area diffraction pattern (SADP) results. A similar structure has been reported in the melt-spun Zr-based amorphous alloys (Xing et al., 2000; Saida et al., 2001), where the icosahedral phase is formed during the crystallization from amorphous phase. They suggest that ordered region is indicative of icosahedral cluster in the as melt-spun ribbon.

Fig. 4A show a bright-field TEM image and corresponding SADP from the $\mathrm{Ti}_{40} \mathrm{Zr}_{29} \mathrm{Be}_{14} \mathrm{Cu}_{9} \mathrm{Ni}_{8}$ ribbon alloy heated up to 763 $\mathrm{K}$. The SADP consists of several ring patterns superimposed on a diffuse halo patterns, indicating a mixture of crystalline and residual amorphous phases. All the ring patterns are analyzed to be an icosahedral phase. The alloy exhibits a random distribution of the icosahedral phase with a typical size of 10 to $15 \mathrm{~nm}$ in the amorphous matrix. Fig. 4B show a HREM image with the incident beam parallel to the five-fold axis and Fourier transformed pattern of the image taken from this alloy. The image showed a homogeneous distribution of sharp bright dots and their straight array on lines parallel to the five-fold directions as well as presence of some residual amorphous phase. The distribution of the bright dots form pentagons of various sizes associated with a scaling of the golden ratio $\tau$, which can be interpreted as the threedimensional Penrose lattice along the five-fold symmetry axis (Hiraga, 1997). Also, the HREM image showed a highly ordered structure of the icosahedral phase without any linear phason strain, which indicates the high structural quality of quasicrystal.

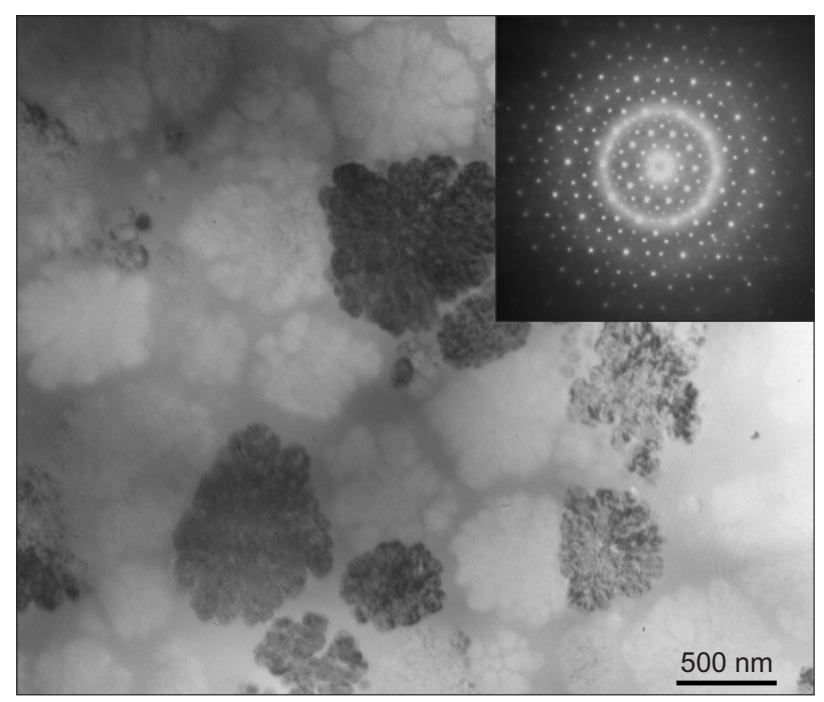

Fig. 5. Bright-field transmission electron microscopy image and selfaligned double patterning of the as injection-cast $\mathrm{Ti}_{40} \mathrm{Zr}_{29} \mathrm{Be}_{14} \mathrm{Cu}_{9} \mathrm{Ni}_{8}$ bulk sample with diameter of $6 \mathrm{~mm}$.

Fig. 5 shows a bright-field TEM image and corresponding SADP from the as injection-cast $\mathrm{Ti}_{40} \mathrm{Zr}_{29} \mathrm{Be}_{14} \mathrm{Cu}_{9} \mathrm{Ni}_{8}$ bulk sample with diameter of $6 \mathrm{~mm}$. The SADP showed the fivefold diffraction symmetry superimposed on a diffuse halo patterns, indicating a mixture of icosahedral and residual amorphous phases. Also, the pattern showed the sharp diffraction spots without diffuse scattering, indicating a reasonably ordered structure. The microstructure consisted of equiaxed dendrites of primary icosahedral phase with size of 300 to $500 \mathrm{~nm}$ and residual amorphous phase. TEM results indicate that in-situ composites consisting of stable icosahedral phase embedded in an amorphous matrix can be formed during solidification from the melt at moderate cooling rate. Above a critical cooling rate, fully amorphous bulk sample was fabricated by injection casting with diameter of $5 \mathrm{~mm}$ for the $\mathrm{Ti}_{40} \mathrm{Zr}_{29} \mathrm{Be}_{14} \mathrm{Cu}_{9} \mathrm{Ni}_{8}$ alloy.

The formation of nano-sized icosahedral phase with large 
volume fraction during the crystallization indicates that the nucleation rate of icosahedral phase is high, which is originated from the existence of the icosahedral cluster in the amorphous phase due to the high stability of the icosahedral short-range order during the solidification from the melt. The existence of stable icosahedral cluster can be understood by structural similarity in short-range order between liquid and the icosahedral phase. It has been reported that the interfacial energy between icosahedral phase and undercooled liquid is small, indicating the similar structure between icosahedral phase and undercooled liquid (Koster et al., 1997).

The local atomic structure of Laves phase is polytetrahedral type, corresponding to a large number of distorted tetrahedral configurations, which is similar to icosahedral configurations (Nelson \& Spaepen, 1989). It has been reported that the solid-liquid interfacial energy decrease with increasing degree of polytetrahedral (or icosahedral) short-range order of the nucleating solid phase (Steinhardt et al., 1983; HollandMoritz et al., 1998). It was estimated that the nucleation rate of icosahedral phase is slightly higher than that of polytetrahedral phase due to the small interfacial energy (Holland-Moritz, 1999). In this study, the formation of icosahedral phase as a primary phase during solidification even though the $\mathrm{MgZn}_{2}$ type C14 Laves phase is stable phase at high temperature is can be explained based on its high nucleation rate relative to that of Laves phase. Also, the formation of high ordered icosahedral phase during solidification is related to existence of icosahedral short-range order in undercooled liquid.

\section{CONCLUSIONS}

In the study, icosahedral phase was formed in the bulk glass forming $\mathrm{Ti}_{40} \mathrm{Zr}_{29} \mathrm{Be}_{14} \mathrm{Cu}_{9} \mathrm{Ni}_{8}$ alloy during crystallization from amorphous phase and solidification from melt. The icosahedral phase forms as a thermodynamically stable phase at lower temperature during crystallization and transforms to Laves and $\beta$-(Ti-Zr) phases through the endothermic reaction at high temperature. The formation of nano-sized icosahedral phase during crystallization indicates the existence of an icosahedral short-range order in the undercooled liquid. The formation of icosahedral phase during solidification from the melt is related to high nucleation rate of icosahedral phase due to lower interfacial energy between icosahedral and liquid phases.

\section{CONFLICT OF INTEREST}

No potential conflict of interest relevant to this article was reported.

\section{REFERENCES}

Hiraga K (1997) High-resolution electron microscopy of quasicrystals. In: Advance in Imaging and Electron Physics, ed. Hawkes P W, Volume 101, pp. 37-98, (Academic Press, New York).

Holland-Moritz D (1999) On the energy of the interface between a melt and quasicrystalline and polytetrahedral phases. J. Non-Cryst. Solids 250-252, 839-843.

Holland-Moritz D, Schroers J, Herlach D M, Grushko B, and Urban K (1998) Undercooling and solidification behaviour of melts of the quasicrystal-forming alloys Al-Cu-Fe and Al-Cu-Co. Acta Mater. 46, 1601-1615.

Holzer J C and Kelton K F (1991) Kinetics of the amorphous to icosahedral phase transformation in AICuV alloys. Acta Metall. Mater. 39, 1833-1843.

Kim W J and Kelton K F (1996) Icosahedral-phase formation and stability in Ti-Zr-Co alloys. Phil. Mag. Lett. 74, 439-447.

Kim Y C, Park J M, Lee J K, Kim W T, and Kim D H (2003a) Role of nanometer-scale quasicrystals in improving the mechanical behavior of Ti-based bulk metallic glasses. Appl. Phys. Lett. 83, 3093-3095.

Kim Y C, Park J M, Lee J K, Kim W T, and Kim D H (2003b) Precipitation of stable icosahedral phase in Ti-based amorphous alloys. Mater. Trans. 44, 1978-1981.

Koster U, Meinhardt J, Roos S, and Busch R (1997) Formation of quasicrystals in bulk glass forming Zr-Cu-Ni-Al alloys. Mater. Sci. Eng. A 226-228, 995-998.

Lee J K, Choi G, Kim W T, and Kim D H (2000) Formation of icosahedral phase from amorphous $\mathrm{Zr}_{65} \mathrm{Al}_{75} \mathrm{Cu}_{125} \mathrm{Ni}_{10} \mathrm{Ag}$ alloys. Appl. Phys. Lett. 77, 978-980.

Mei J N, Li J S, Kou H C, Fu H Z, and Zhou L (2008) Effects of Nb on the formation of icosahedral quasicrystalline phase in Ti-rich Ti-Zr-Ni-CuBe glassy forming alloys. J. Non-Cryst. Solids 354, 3332-3335.

Nelson D R and Spaepen F (1989) Polytetrahedral order in condensed matter. In: Solid State Physics, eds. Enrenreich $\mathrm{H}$ and Turnbull D, Volume 42, pp. 1-90, (Academic Press, San Diego).

Park J M, Chang H J, Han K H, Kim W T, and Kim D H (2005) Enhancement of plasticity in Ti-rich Ti-Zr-Be-Cu-Ni bulk metallic glasses. Scripta Mater. 53, 1-6.

Poon S J, Drehman A J, and Lawless K R (1985) Glassy to icosahedral phase transformation in Pd-U-Si alloys. Phys. Rev. Lett. 55, 2324-2327.

Qiang J B, Zhang W, and Inoue A (2006) Formation of glassy and icosahedral phases in as-cast $\left(\mathrm{Zr}_{9} \mathrm{Ni}_{4}\right)_{75}\left(\mathrm{Al}_{1-x} \mathrm{Ti}_{x}\right)_{25}$ alloys. Scripta Mater. 55, 617-620.

Ren H T, Pan J, Chen Q, Chan K C, Liu Y, and Liu L (2011) Enhancement of plasticity and toughness in monolithic Zr-based bulk metallic glass by heterogeneous microstructure. Scripta Mater. 64, 609-612.

Saida J, Matsushita M, and Inoue A (2000) Nanoscale icosahedral quasicrystalline phase formation in a rapidly solidified $\mathrm{Zr}_{80} \mathrm{Pt}_{20}$ binary alloy. Appl. Phys. Lett. 77, 73-75.

Saida J, Matsushita M, and Inoue A (2001) Direct observation of icosahedral cluster in Zr70Pd30 binary glassy alloy. Appl. Phys. Lett. 79, $412-414$ 
Shechtman D, Blech I, Gratias D, and Chan J W (1984) Metallic phase with long-range orientational order and no translational symmetry. Phys. Rev. Lett. 53, 1951-1953.

Steinhardt P J, Nelson D R, and Ronchetti M (1983) Bond-orientational order in liquids and glasses. Phys. Rev. B 28, 784-805.

Tsai A P, Inoue A, Bizen Y, and Masumoto T (1989) Kinetics of the amorphous to icosahedral structure transition in Al-Cu-V and Al-Mn-Si alloys. Acta Metall. 37, 1443-1449.

Xing L Q, Eckert J, Loser W, and Schultz L (1999) High-strength materials produced by precipitation of icosahedral quasicrystals in bulk Zr-TiCu-Ni-Al amorphous alloys. Appl. Phys. Lett. 74, 664-666.

Xing L Q, Hufnagel T C, Eckert J, Loser W, and Schultz L (2000) Relation between short-range order and crystallization behavior in Zr-based amorphous alloys. Appl. Phys. Lett. 77, 1970-1972.

Xing $L$ Q, Shen $Y T$, and Kelton K F (2002) Precipitation of an icosahedrally symmetric ordered phase in Zr-Ti-Cu-Ni-Al metallic glasses. Appl. Phys. Lett. 81, 3371-3373. 